\title{
Hepatoprotective and immunomodulatory effects of copper-nicotinate complex against fatty liver in rat model
}

\author{
Ahmed Medhat Hegazy ${ }^{1}$, Ayman Samir Farid ${ }^{2}$, Ahmed S. Hafez ${ }^{3}$, Rania M. Eid ${ }^{4}$ and Soad M. Nasr ${ }^{5}$
}

1. Department of Forensic Medicine and Toxicology, Faculty of Veterinary Medicine, Aswan University, Sahari, Airport Way 81528, Aswan, Egypt; 2. Department of Clinical Pathology, Faculty of Veterinary Medicine, Benha University, Moshtohor, Toukh 13736, Qalyubia, Egypt; 3. Department of Pharmacology, Faculty of Veterinary Medicine, Aswan University, Sahari, Airport Way 81528, Aswan, Egypt; 4. Department of Physiology, Faculty of Medicine, Aswan University, Sahari, Airport Way 81528, Aswan, Egypt; 5. Department of Parasitology and Animal Diseases, National Research Centre, 33 Bohouth Street, Post Box 12622, Dokki, Giza, Egypt.

Corresponding author: Ahmed Medhat Hegazy, e-mail: ahmed_medhat012@yahoo.com

Co-authors: ASF: ayman.samir@fvtm.bu.edu.eg, ASH: asaiedhafez@yahoo.com, RME: rania.eid@aswu.edu.eg, SMN: soadnasr@yahoo.com

Received: 29-07-2019, Accepted: 23-10-2019, Published online: 04-12-2019

doi: www.doi.org/10.14202/vetworld.2019.1903-1910 How to cite this article: Hegazy AM, Farid AS, Hafez AS, Eid RM, Nasr SM (2019) Hepatoprotective and immunomodulatory effects of copper-nicotinate complex against fatty liver in rat model, Veterinary World, 12(12): 1903-1910.

\begin{abstract}
Aim: The current study was designed to evaluate the potential hepatoprotective and immunomodulatory effects of coppernicotinate complex (CNC) against methionine- and choline-deficient diet (MCDD)-induced fatty liver in rats.

Materials and Methods: Forty male Wistar rats were randomly allocated into one of four equal-sized groups (G1-G4). The G1 group was fed a balanced diet and kept under normal conditions; the G2 group received CNC orally at a dose of $0.043 \mathrm{mg} / \mathrm{kg}$ body weight, 3 times/week for 4 weeks, and a balanced diet; the G3 group was fed an MCDD for 4 weeks; and the G4 group was fed an MCDD and administered CNC at the same dose and route as G2. Blood samples were collected for the determination of serum enzyme activity. After 4 weeks of treatment, liver specimens were collected for the evaluation of the oxidative/antioxidative markers, cytokine gene expression, and histopathological examination.
\end{abstract}

Results: CNC improved MCDD-induced liver dysfunctions by recovering serum alanine aminotransferase, aspartate aminotransferase, and gamma-glutamyl transferase activities to their normal levels. The glutathione (GSH) level and superoxide dismutase (SOD) activity significantly decreased, while lipid peroxidation (as reflected by malondialdehyde [MDA]) markedly increased in the liver tissue of the MCDD group. After cotreatment with MCDD and CNC, the GSH level and SOD activity markedly increased and the MDA level significantly decreased to return to normal levels. After cotreatment with MCDD and CNC, significant downregulation of the mRNA expression of hepatic interleukin (IL)-1 $\beta$, IL-4, macrophage inflammatory protein- $1 \alpha$, and monocyte chemoattractant protein- 1 genes was found. Moreover, CNC reduced fatty liver complications by reducing the number of hepatic vacuolations, degenerative changes in the hepatocytes, and hemorrhage.

Conclusion: $\mathrm{CNC}$ has the potential to limit tissue injury and possibly prevent the progression to severe liver disease caused by an MCDD.

Keywords: copper-nicotinate complex, cytokines gene expression, fatty liver, hepatoprotective, oxidative stress markers.

\section{Introduction}

Non-alcoholic fatty liver disease (NAFLD) is the most common chronic liver disorder across the world. It has a prevalence of approximately $20 \%$ in the general population and up to $95 \%$ in people with obesity. This liver disease includes mild-to-severe steatosis, steatohepatitis, hepatocellular injury, progressive chronic inflammation, and fibrosis [1]. NAFLD occurs due to morphologic and functional alterations of the mitochondria, an increase of inflammatory activity, oxidative stress, generation of reactive

Copyright: Hegazy, et al. Open Access. This article is distributed under the terms of the Creative Commons Attribution 4.0 International License (http://creativecommons.org/licenses/ by/4.0/), which permits unrestricted use, distribution, and reproduction in any medium, provided you give appropriate credit to the original author(s) and the source, provide a link to the Creative Commons license, and indicate if changes were made. The Creative Commons Public Domain Dedication waiver (http:// creativecommons.org/publicdomain/zero/1.0/) applies to the data made available in this article, unless otherwise stated. oxygen species, and lipid peroxidation [2]. Metabolic disorders such as insulin resistance, dyslipidemia, and visceral obesity are the main risk factors for NAFLD.

A methionine- and choline-deficient diet (MCDD) is used in rodents to induce NAFLD. Choline is a nutrient that influences lipid metabolism [3] through lipid second messengers [4], methylation-dependent biosynthesis of molecules including those in regulation of gene expression [5], activation of nuclear receptors [6], enterohepatic circulation of bile and cholesterol [7], plasma membrane fluidity [8], and mitochondrial bioenergetics [9]. Methionine is essential for the growth, repair, and metabolism of all tissues. In the diet, the methionine level is important in relation to the need for choline as a methyl donor [10]. Nutritional models based on MCDD lead to the impaired formation of very low-density lipoproteins, inducing pathogenic events such as the early accumulation of triglycerides in the liver (fatty liver) with 
increased lipid peroxidation followed by inflammation and hepatic fibrosis [11]. Copper is an essential trace element. It is a cofactor for many enzymes that are essential for respiration, bone formation, and development of connective tissue, and an essential catalytic cofactor of some metalloenzymes [12]. Deficiency of certain vitamins, such as nicotinic acid, has deleterious effects [13]. Copper-nicotinate complex (CNC) is a biologically active copper-chelating complex that exhibits superoxide dismutase (SOD)-mimicking activity, anti-inflammatory action in gastric ulcer [14], and reduction of hepatocellular carcinoma [15], acts a rheumatoid arthritis treatment [16], improves skin burns [17], ameliorates nephrotoxicity resulting from the topical application of glycerol [14], and protects against neuronal and glial cell injuries [18].

Therefore, this study was conducted to evaluate the potential hepatoprotective and immunomodulatory effects of CNC in Wistar rats exposed to MCDDinduced fatty liver.

\section{Materials and Methods}

\section{Ethical approval}

This experiment was carried out according to the guidelines of the Institutional Animal Ethics Committee, Benha University, Egypt, and Approval Protocol No.: 44 on April 10, 2016.

\section{CNC}

CNC was provided as a gift by Professor Dr. Ahmed Yassen Nassar, Professor of Biochemistry, Faculty of Science, Assiut University, Egypt. The complex was administered to rats at a dose of $0.043 \mathrm{mg} / \mathrm{kg}$ body weight, 3 times/week, continuously for 4 weeks, according to a previously described method [14].

\section{Composition of diets}

The balanced diet composition (Table-1) was formulated according to the National Research Council (NRC) [19]. It contained crude protein (15\%), metabolizable energy (ME) (3800 kcal $/ \mathrm{kg}$ diet), choline $(1342 \mathrm{ppm})$, and methionine $(0.32 \%)$, as shown in Table-2.

The MCDD (Table-3) was formulated according to the NRC [19]. It contained crude protein (15\%), ME (3800 kcal $/ \mathrm{kg}$ diet), choline (575 ppm), and methionine $(0.24 \%)$, as shown in Table-2.

\section{Experimental animals}

Five-week-old male Wistar rats (120-140 g) were obtained from the Animal House, National Cancer Institute, Cairo, Egypt. All animals were housed in clean cages and given food and water ad libitum. Their environmental conditions were controlled in terms of light (12 h light-dark cycle starting at 8:00 a.m.) and room temperature $\left(23 \pm 3^{\circ} \mathrm{C}\right)$.

\section{Experimental design}

Forty male Wistar rats were randomly allocated into one of four groups (10 rats per group). The first group (G1) was kept as the control and fed a balanced diet. The second group (G2) was given $\mathrm{CNC}$ at a dose
Table-1: Ingredients of the balanced diet.

\begin{tabular}{lc}
\hline Feed ingredients & Diet (\%) \\
\hline Sunflower oil & 15.000 \\
Concentrate mixture (45\%) & 10.000 \\
Yellow corn & 49.000 \\
Soybean meal (44\%) & 11.000 \\
Wheat bran & 10.000 \\
Molasses & 03.000 \\
Common salt & 00.500 \\
Ground limestone & 00.200 \\
Dicalcium phosphate & 00.100 \\
Lysine & 00.200 \\
DL-methionine & 00.700 \\
Mineral-vitamin premix & 00.300 \\
Total & 100.000 \\
\hline
\end{tabular}

Table-2: Chemical constituents of the balanced and MCDD.

\begin{tabular}{lcc}
\hline Item & Balanced diet & MCDD \\
\hline Crude protein (\%) & 15.000 & 15.000 \\
Metabolizable energy & 3800 & 3800 \\
(kcal/kg diet) & & \\
Methionine (\%) & 0.320 & 0.240 \\
Choline (ppm) & 1342 & 575 \\
\hline
\end{tabular}

$M C D D=$ Methionine- and choline-deficient diet

Table-3: Ingredients of the methionine- and cholinedeficient diet.

\begin{tabular}{lc}
\hline Feed ingredients & Diet $(\boldsymbol{\%})$ \\
\hline Corn & 58.275 \\
Soya 46\% & 21.900 \\
Oil & 15.000 \\
Limestone & 1.200 \\
Sucrose & 3.000 \\
Lysine & 0.200 \\
Common salts & 0.125 \\
Premix choline free & 0.300 \\
Total & 100.000 \\
\hline
\end{tabular}

of $0.043 \mathrm{mg} / \mathrm{kg}$ body weight orally through a stomach tube 3 times/week continuously for 4 weeks and fed a balanced diet. The third group (G3) was fed an MCDD for 4 weeks continuously. The fourth group (G4) was fed an MCDD continuously for 4 weeks and given CNC orally through a stomach tube $(0.043 \mathrm{mg} / \mathrm{kg}$ body weight) 3 times/week continuously for 4 weeks. Clinical signs were recorded for all groups during the experimental period. At the end of the $4^{\text {th }}$ week of the experiment, blood samples were collected from the retro-orbital venous plexus of each rat. Each blood sample was placed in a plain centrifuge tube for the separation of the serum. The serum samples were stored at $-20^{\circ} \mathrm{C}$ for further enzyme analyses. At the end of the $4^{\text {th }}$ week of the experiment, the rats were euthanized. Three portions of liver specimens were collected from all rats in each group. The first and second portions of the liver specimen were stored at $-70^{\circ} \mathrm{C}$ for further evaluation of the oxidative/antioxidative markers and cytokine gene expression. The third portion of the liver specimens was collected and fixed in 10\% formal saline for histopathological examinations. 


\section{Preparation of liver homogenates}

Preparation of liver tissue homogenates was performed according to a previously published study [20]. Liver homogenate (prepared from $1 \mathrm{~g}$ of hepatic tissue) was obtained from all rats at the end of the $4^{\text {th }}$ week of the experiment, washed, and homogenized in an ice-cold $1.15 \%$ solution of potassium chloride in $50 \mathrm{mmol}$ potassium phosphate buffer solution ( $\mathrm{pH} 7.4)$ to obtain a $10 \%$ liver homogenate $(\mathrm{W} / \mathrm{V}$; weight of liver tissue [g] per volume of the buffer [ml]). Homogenization of the liver tissue was performed using a Sonicator (4710 Ultrasonics Homogenizer, Cole-Parmer Instrument Co., USA). The homogenate was then centrifuged (Sigma 30K refrigerated centrifuge; Sigma-Aldrich Co., St. Louis, $\mathrm{MO}$, USA) at $4000 \mathrm{rpm}$ for $5 \mathrm{~min}$ at $4^{\circ} \mathrm{C}$. The collected supernatant was used in the determination of the concentration of reduced glutathione (GSH) and lipid peroxidation byproducts and determination of the SOD activity.

\section{Assay methods}

Determination of serum liver enzymes

Colorimetric determination of the alanine aminotransferase (ALT) and aspartate aminotransferase (AST) activity was performed according to a previously described method [21]. The activity of gamma-glutamyl transferase (GGT) was also assessed according to a previously published method [22].

\section{Determination of oxidative/antioxidative markers in liver homogenates}

The reduced GSH content was measured according to the method described by Ellman [23]. The reduced chromogen is directly proportional to the GSH concentration and its absorbance was measured at $405 \mathrm{~nm}$ using a spectrophotometer (Model, JASCO 7800, UV/VIS, Japan). Concentrations of GSH are expressed as $\mu \mathrm{mol} / \mathrm{mg}$ protein. SOD activity was measured according to the method described by Misra and Fridovich [24]. The enzyme activity was determined by considering the degree of inhibition of the autoxidation of epinephrine in alkaline medium. SOD activity is expressed as unit/mg protein. Lipid peroxidation byproducts in liver tissue homogenates were determined according to the method described by Ohkawa et al. [25], which depend on the formation of malondialdehyde (MDA) as an end product of lipid peroxidation that reacts with thiobarbituric acid-producing thiobarbituric acid reactive substance, a pink chromogen that can be measured spectrophotometrically at $535 \mathrm{~nm}$. An MDA standard was used to construct a standard curve against which readings of the samples were plotted. Concentrations of lipid peroxides are expressed as $\mathrm{nmol} / \mathrm{mg}$ protein. The total protein content of the homogenates was determined using the method described by Lowry et al. [26].

Analysis of mRNA expression of hepatic interleukin (IL)-1 $1 \beta$, IL-4, IL-10, monocyte chemoattractant protein (MCP)-1, and macrophage inflammatory protein (MIP)-1 $\alpha$ genes using real-time polymerase chain reaction (PCR).

The expression of hepatic IL-1 $\beta$, IL-4, IL-10, MCP-1, and MIP-1 $\alpha$ cytokines was analyzed using real-time PCR with sense and antisense primers throughout the experiment as previously described [27] using the following primers sets: IL-1 $\beta$ (GenBank ID: M98820.1), sense (5'-CAC CTC TCA AGC AGA GCA CAG-3') and antisense (5'-GGG TTC CAT GGT GAA GTC AAC-3'); IL-4, sense (5'-CAG GGT GCT TCG CAA ATT TTA C-3') and antisense (5'- ACCG AGA ACC CCA GAC TTG TT-3'); IL-10 (GenBank ID: L02926.1), sense (5'-AGA AGC TGA AGA CCC TCT GGA TAC-3') and antisense (5'-GCT CCA CTG CCT TGC TTT TAT T-3'); MCP-1, sense (5'- ATG CAG TTA ATG CCC CAC TC- $3^{\prime}$ ) and antisense (5'- TTC CTT ATT GGG GTC AGC AC-3'); MIP-1 $1 \alpha$, sense (5'CAT TCC TGC CAC CTG CAA AT-3') and antisense (5'- CAA GTG AAG AGT CCC TGG ATG TG-3'); and $18 \mathrm{~S}$ rRNA as a housekeeping gene, sense (5'-GAG GTG AAA TTC TTG GAC CGG-3') and antisense (5'CGA ACC TCC GAC TTT CGT TCT-3').

Thermal cycling and fluorescence detection were performed using a 7300 real-time PCR system (Applied Biosystems, Foster City, CA, USA). Changes in gene expression were calculated from the obtained cycle threshold $\left(\mathrm{C}_{t}\right)$ values provided by the real-time PCR instrumentation using the comparative $\mathrm{C}_{\mathrm{t}}$ method to a reference (housekeeping) gene (18S rRNA) [28].

\section{Histopathological examinations}

Tissue samples were taken from the liver of rats in the different groups and fixed in neutral buffered formalin $(10 \%)$. Washing was performed using tap water; serial dilutions of alcohol were then used for dehydration. Specimens were cleared in xylene and embedded in paraffin at $56^{\circ} \mathrm{C}$ in a hot air oven for $24 \mathrm{~h}$. Paraffin beeswax tissue blocks were prepared for sectioning at $4-\mu \mathrm{m}$ thickness. The obtained tissue sections were collected on glass slides, deparaffinized, and stained with hematoxylin and eosin [29] for histopathological examination using light microscopy.

\section{Statistical analysis}

Statistical analysis was performed using the Statistical Software Package (SPSS) for Windows (Version 20.0; SPSS Inc., Chicago, IL, USA). The significance of differences between the groups was evaluated using one-way analysis of variance followed by Duncan's multiple range test. Differences were considered significant at $\mathrm{p}<0.05$ level. All data are expressed as mean \pm standard deviation.

\section{Results}

No mortality was recorded during the period of the experiment.

\section{Changes in serum liver enzymes}

After 4 weeks of treatment, ALT, AST, and GGT activities were significantly $(\mathrm{p}<0.01)$ higher in the 
fatty liver group fed MCDD (G3) compared to those in control (G1) and CNC-treated (G2) groups. On the other hand, when compared to both the control (G1) and $\mathrm{CNC}$ alone (G2) groups, the group fed with MCDD and cotreated with CNC (G4) showed recovery of ALT, AST, and GGT levels to normal values (Table-4).

\section{Changes in the hepatic oxidative/antioxidative markers}

The GSH and SOD activities in the liver tissue of the MCDD-treated group were significantly $(p<0.05)$ lower than those in the control and CNCtreated groups, while the MCDD group cotreated with $\mathrm{CNC}$ exhibited recovery of the enzymatic activities to normal levels after the $4^{\text {th }}$ week of the experiment. Likewise, the level of MDA, a marker of lipid peroxidation, in liver tissue was markedly $(\mathrm{p}<0.01)$ higher in the MCDD-treated group compared to that in the control and CNC-treated groups, while the MCDD group cotreated with $\mathrm{CNC}$ demonstrated recovery of MDA levels to normal values after the $4^{\text {th }}$ week of the experiment (Table-5).

Changes in hepatic IL-1 $\beta$, IL-4, IL-10, MCP-1, and MIP-1a mRNA expression

To evaluate the molecular mechanisms underlying the immunomodulatory properties of $\mathrm{CNC}$, the mRNA expression of hepatic tissue was investigated (Figure-1). IL-1 $\beta$, IL-4, MCP-1, and MIP- $1 \alpha$ gene expression were significantly upregulated in the fatty liver group (G3) relative to expression in the control group (G1). Meanwhile, there was a non-significant difference in IL-10 expression in the fatty liver group (G3) relative to that in the control group. However, the group cotreated with CNC and MCDD (G4) exhibited significant downregulations in IL-1 $\beta$, IL-4, MCP-1, and MIP- $1 \alpha$ relative to that in the fatty liver group (G3). Both groups that received CNC (G2 and G4) showed significant upregulation in IL-10 expression relative to that in both the control (G1) and fatty liver (G3) groups.

\section{Histopathological findings}

The liver of rats in the control group (G1) (Figure-2a) showed normal histological structures. Furthermore, no histopathological alterations were noticed in the liver of rats $(\mathrm{G} 2)$ that received $\mathrm{CNC}$ (Figure-2b). In the fatty liver group fed MCDD (G3), the liver showed defuses hepatic vacuolations and centrilobular hepatic degeneration with hemorrhage. The vacuolation was suspected to be fat accumulation (Figure-2c). However, the liver of rats that received both MCDD (fatty liver) and CNC (G4) appeared normal with mild-to-moderate hepatic vacuolations (Figure-2d).

\section{Discussion}

NAFLD is associated by many with metabolic syndrome [30]. The diagnosis of NAFLD occurs after finding raised aminotransferase levels, fatty liver, or hepatomegaly [31].

In this study, the fatty liver group of rats (G3) exposed to MCDD showed no clinical signs of toxicity. Importantly, there were significant elevations in the ALT, AST, and GGT activities in the serum of the G3 group. Increased levels of these enzymes in the serum may be due to hepatocellular damage induced by the early accumulation of lipid and to a lesser extent on inflammatory processes. Similar results have been previously reported [32].

The main mechanism of MCDD-induced liver steatosis in the rat model is impaired phosphatidylcholine synthesis, which is essential for the secretion of hepatic very low-density lipoproteins [33].

On the other hand, there was a significant decrease in the ALT, AST, and GGT activities in the serum of rats cotreated with MCDD and CNC (G4). This decrease may be due to the hepatoprotective activity of CNC. CNC may act by preventing further oxidative stress (free radical accumulation) in the fatty liver [34]. CNC also enhances the synthesis of SOD or its SOD mimetic activity leads to scavenging of oxygen free radicals. CNC exhibits lipophilic activity that

Table-4: Effect of CNC on liver enzyme activity in the serum of rats with fatty liver (mean \pm standard deviation, $\mathrm{n}=10$ ).

\begin{tabular}{lcccc}
\hline Group parameters & Normal control (G1) & CNC (G2) & MCDD (G3) & CNC+MCDD (G4) \\
\hline ALT (IU/I) & $24.169 \pm 1.245^{\mathrm{b}}$ & $25.966 \pm 2.123^{\mathrm{b}}$ & $48.121 \pm 0.924^{\mathrm{a}}$ & $28.488 \pm 2.659^{\mathrm{b}}$ \\
AST (IU/I) & $118.944 \pm 4.219^{\mathrm{b}}$ & $124.478 \pm 3.651^{\mathrm{b}}$ & $176.358 \pm 9.347^{\mathrm{a}}$ & $134.604 \pm 3.802^{\mathrm{b}}$ \\
GGT (IU/I) & $4.892 \pm 0.428^{\mathrm{b}}$ & $4.666 \pm 0.462^{\mathrm{b}}$ & $9.506 \pm 0.252^{\mathrm{a}}$ & $4.756 \pm 0.882^{\mathrm{b}}$ \\
\hline
\end{tabular}

Means with different superscripts in the same row are significantly different at $p<0.05$. CNC $=$ Copper-nicotinate complex, $\mathrm{MCDD}=$ Methionine- and choline-deficient diet, $\mathrm{ALT}=$ Alanine aminotransferase, $\mathrm{AST}=$ Aspartate aminotransferase, GGT=Gamma glutamyl transferase

Table-5: Effect of CNC on oxidative/antioxidative markers in liver homogenate of rats with fatty liver (mean \pm standard deviation, $n=10)$.

\begin{tabular}{lcccc}
\hline Group parameters & Normal control (G1) & CNC (G2) & MCDD (G3) & CNC+MCDD (G4) \\
\hline Glutathione reduced ( $\mu$ mol/mg protein) & $16.858 \pm 1.777^{\mathrm{a}}$ & $19.199 \pm 4.177^{\mathrm{a}}$ & $6.003 \pm 4.325^{\mathrm{b}}$ & $13.569 \pm 2.621^{\mathrm{a}}$ \\
Superoxide dismutase (unit/mg protein) & $0.038 \pm 0.008^{\mathrm{b}}$ & $0.056 \pm 0.004^{\mathrm{a}}$ & $0.007 \pm 0.002^{\mathrm{c}}$ & $0.032 \pm 0.006^{\mathrm{b}}$ \\
Malondialdehyde (nmol/mg protein) & $10.777 \pm 1.384^{\mathrm{b}}$ & $10.867 \pm 2.572^{\mathrm{b}}$ & $26.671 \pm 5.911^{\mathrm{a}}$ & $14.454 \pm 2.102^{\mathrm{b}}$ \\
\hline
\end{tabular}

Means with different superscripts in the same row are significantly different at $p<0.05$. CNC $=$ Copper-nicotinate complex, $M C D D=$ Methionine- and choline-deficient diet 


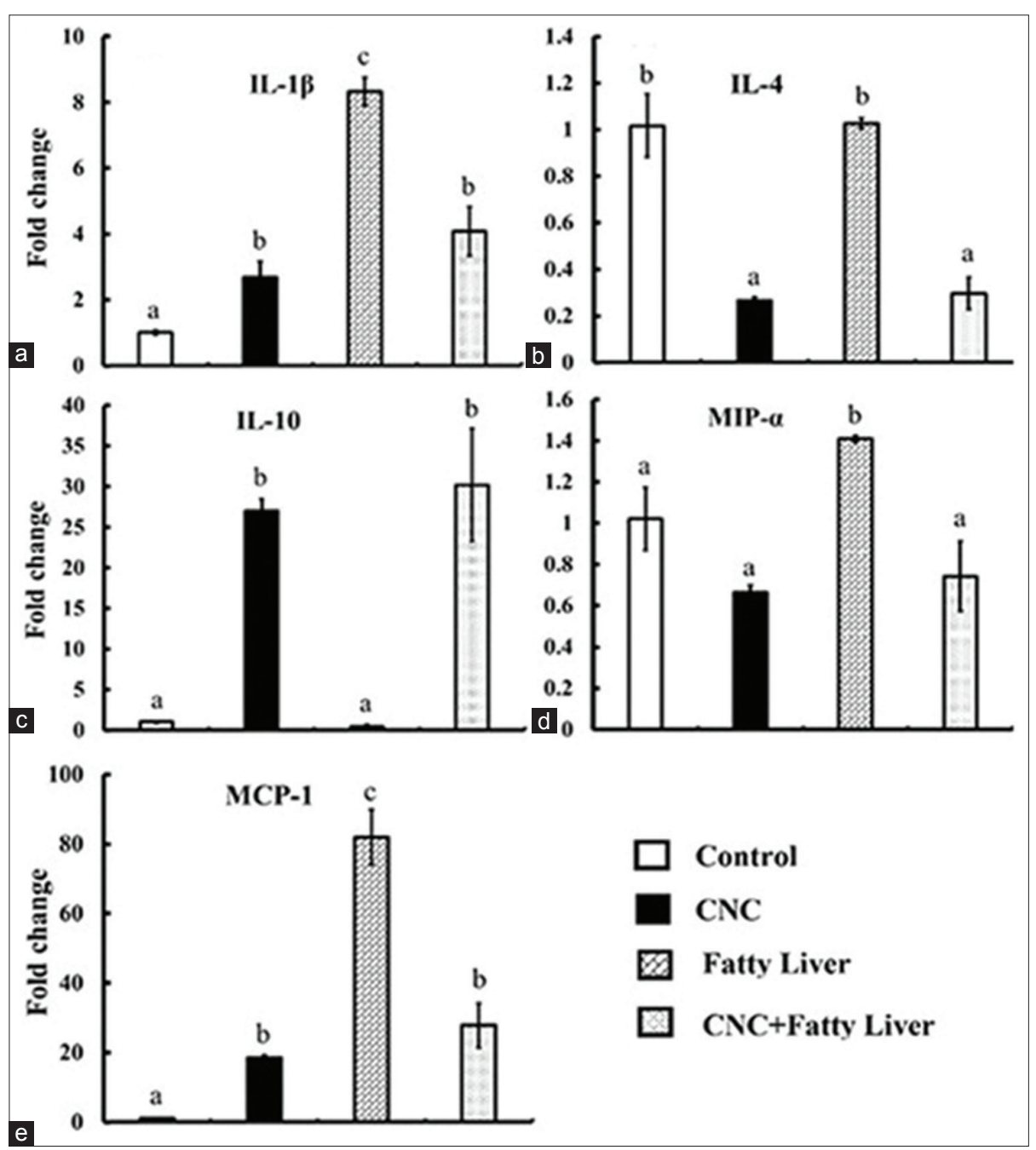

Figure-1: mRNA expression of hepatic interleukin (IL)-1ß, IL-4, IL-10, macrophage inflammatory protein-1a, and monocyte chemoattractant protein-1 genes in different experimental groups. Total RNA was prepared from hepatic tissues of each rat group after 4 weeks of treatment. The expression levels were evaluated using real-time polymerase chain reaction. $* p<0.05$ compared with control values. Bars represent means \pm standard error $(n=4)$.

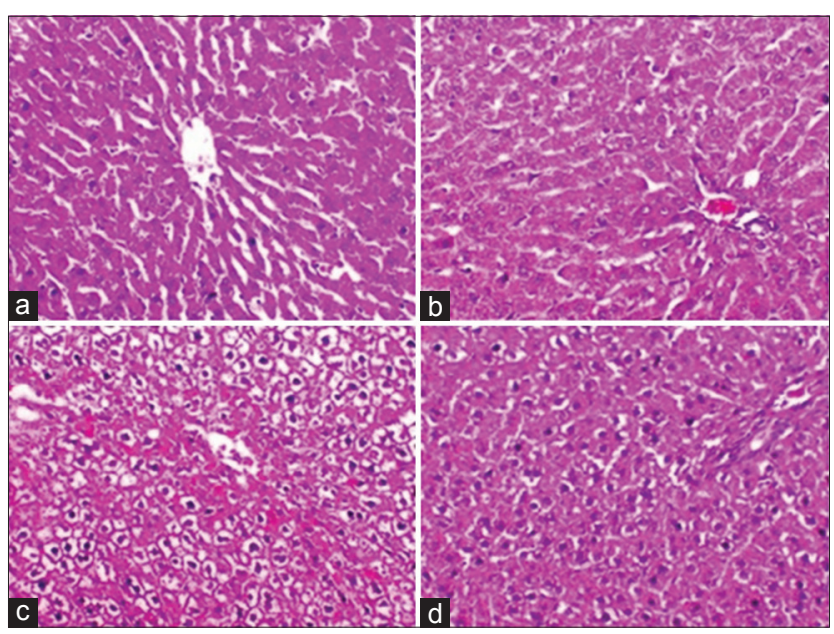

Figure-2: Liver sections of rats. (a) Control group (G1) exhibited normal histological structure. (b) Coppernicotinate complex (CNC) group (G2) exhibited normal histological structure of the hepatocytes in the hepatic cords with central veins. (c) Methionine- and cholinedeficient diet (MCDD) group (G3) exhibited diffuse hepatic vacuolation and centrolobular hepatic degeneration with hemorrhage. (d) CNC with MCDD group (G4) exhibited mild-to-moderate hepatic vacuolation (hematoxylin and eosin, 200x). enhances its migration toward the intracellular space of hepatic tissue. It acts as a mediator for cellular copper-dependent enzymes [35].

In the present study, there was an increase in lipid peroxidation, as indicated by an elevation in the MDA level, and decrease in the GSH level and SOD activity in rats that received MCDD after the $4^{\text {th }}$ week of treatment. This might be due to the peroxidation of cell membrane lipids and injury to the cellular components [14]. A reduction in the MDA level and increase in the GSH level and SOD activity were observed with MCDD and CNC cotreatment. CNC is a rich source of antioxidants [36] and seems to be more efficient as detoxifying agent [37]. Its detoxifying action is attributed to its scavenging of free radicals, exhibiting SOD-mimicking activity [14].

Oxidative stress has been recorded in several liver diseases. It also triggers the production of inflammatory cytokines, causing inflammation, and fibrogenic response injury [38]. The presence of inflammation can predict the progression of non-alcoholic steatohepatitis (NASH) to advanced fibrosis [39]. Many cytokines have been suggested to play an essential pathogenic 
role in NAFLD [40]. In addition, lipid peroxidation end products are potent chemoattractants for inflammatory cells [41] and can activate hepatic stellate cells and hence stimulate hepatic fibrosis [42].

In the present study, we found a significant increase in the expression of hepatic IL- $1 \beta$ in the group with a fatty liver when compared with that in the control group. IL-4 is an anti-inflammatory cytokine. It stimulates lymphocytic differentiation into Th2 cells, contributing to the development of fibrosis and consequent hepatic injury repair [43]. IL-4 is involved in tissue repair and the control of Th1 responses through the alternative activation of macrophages [44]. Thus far, several previous studies have demonstrated that IL-4 may have a pro- or anti-inflammatory role in the development of organ-specific inflammation in classical autoimmune disease models. In experimental immune-mediated hepatitis, a pro-inflammatory role of IL-4 is heavily supported [45]. In this study, the hepatic IL-4 mRNA expression of rats that received CNC (G2 and G4) was very low, while that of IL-10 was high. IL-10 (cytokine synthesis inhibitory factor) is a cross-regulatory factor of Th1 and Th2 responses. It is produced by Th2 cells [46]. In liver tissue, IL-10 may act as an anti-inflammatory mediator against necroinflammatory lesions [47].

The $\beta$-chemokines are exclusively chemotactic for mononuclear cells; archetypes of this group, $\mathrm{MCP}-1$ and MIP- $1 \alpha$, are monocyte and lymphocyte chemoattractants [48]. Both TNF- $\alpha$ and IL-1 are potent inducers of MCP-1 [49]. In the liver inflammatory process, MCP-1 may directly cause impairment of hepatocyte proliferation [50]. It regulates the migration of monocytes into tissues and their subsequent differentiation into macrophages [51]. MCP-1 may play an important role in the stimulation of the inflammatory infiltrate. It might also have immunomodulatory effects including enhanced expression of adhesion molecules in monocytes and promotion of a pro-inflammatory cytokine synthesis [52]. In this study, MCP-1 was significantly higher in the fatty liver group (G3) and closer to normal levels in the presence of CNC treatment (G4).

These findings were corroborated by those of the histopathological examination. It revealed the improvement in histopathological features in the liver of CNC-treated rats (G4) compared to the liver of MCDD-treated rats (G3), which showed diffuse hepatic vacuolation, centrilobular hepatic degeneration, and hemorrhage. The vacuolation was suspected to be due to fat accumulation. Mild-to-moderate hepatic vacuolations were noticed in cotreated group (G4). These findings coincide with those of the previous study [53] that fed rats a high carbohydrate, fatfree semi-synthetic diet, and cotreated with CNC.

\section{Conclusion}

This study provides new evidence about the role of $\mathrm{CNC}$ as a hepatoprotective and immunomodulatory agent that might represent a novel therapeutic target in NASH with the potential to limit tissue injury and possibly prevent the progression to severe liver disease.

\section{Authors' Contributions}

AMH designed the study, collected the samples, analyzed the data, and wrote the manuscript. ASF applied PCR testing and revised all manuscripts. ASH obtained the CNC. RME and SMN revised and approved the final manuscript.

\section{Acknowledgments}

The authors are grateful to Professor Dr. Nasser El-Saied Khedr, Professor of Clinical Nutrition, Faculty of Veterinary Medicine, Benha University, Egypt, and to Professor Dr. Ahmed Yassen Nassar, Professor of Biochemistry, Faculty of Science, Assiut University, Egypt, for their valuable support and also thank the staff of the Department of Forensic Medicine and Toxicology, Faculty of Veterinary Medicine, Benha University, Egypt, for their help. The authors did not receive any funding for this study.

\section{Competing Interests}

The authors declare that they have no competing interests.

\section{Publisher's Note}

Veterinary World remains neutral with regard to jurisdictional claims in published institutional affiliation.

\section{References}

1. Deminice, R., de Castro, G.S., Francisco, L.V., da Silva, L.E., Cardoso, J.F., Frajacomo, F.T., Teodoro, B.G., Dos Reis Silveira, L. and Jordao, A.A. (2015) Creatine supplementation prevents fatty liver in rats fed choline-deficient diet: A burden of one-carbon and fatty acid metabolism. J. Nutr. Biochem., 26(4): 391-397.

2. Asgharpour, A., Cazanave, S.C., Pacana, T., Seneshaw, M., Vincent, R., Banini, B.A., Kumar, D.P., Daita, K., Min, H.K., Mirshahi, F., Bedossa, P., Sun, X., Hoshida, Y., Koduru, S.V., Contaifer, D. Jr., Warncke, U.O., Wijesinghe, D.S. and Sanyal, A.J. (2016) A diet-induced animal model of non-alcoholic fatty liver disease and hepatocellular cancer. $J$. Hepatol., 65(3): 579-588.

3. Jiang, X., West, A.A. and Caudill, M.A. (2014) Maternal choline supplementation: A nutritional approach for improving offspring health? Trends Endocrinol. Metab., 25(5): 263-273.

4. Palmer, J.D., Soule, B.P., Simone, B.A., Zaorsky, N.G., Jin, L. and Simone, N.L. (2014) MicroRNA expression altered by diet: Can food be medicinal? Ageing Res. Rev., $17: 16-24$

5. Zeisel, S. (2017) Choline, other methyl-donors and epigenetics. Nutrients, 9(5): E445.

6. Furse, S. and de Kroon, A.I. (2015) Phosphatidylcholine's functions beyond that of a membrane brick. Mol. Membr. Biol., 32(4): 117-119.

7. Zhou, X., Levin, E.J., Pan, Y., McCoy, J.G., Sharma, R., Kloss, B., Bruni, R., Quick, M. and Zhou, M. (2014) Structural basis of the alternating-access mechanism in a bile acid transporter. Nature, 505(7484): 569-573.

8. Noureddin, M., Mato, J.M. and Lu, S.C. (2015) Nonalcoholic fatty liver disease: Update on pathogenesis, diagnosis, treatment and the role of S-adenosylmethionine. Exp. Biol. Med. (Maywood), 240(6): 809-820. 
9. Feillet-Coudray, C., Fouret, G., Casas, F. and Coudray, C. (2014) Impact of high dietary lipid intake and related metabolic disorders on the abundance and acyl composition of the unique mitochondrial phospholipid, cardiolipin. J. Bioenerg. Biomembr., 46(5): 447-457.

10. Pacana, T., Cazanave, S., Verdianelli, A., Patel, V., Min, H.K., Mirshahi, F., Quinlivan, E. and Sanyal, A.J. (2015) Dysregulated hepatic methionine metabolism drives homocysteine elevation in diet-induced nonalcoholic fatty liver disease. PLoS One, 10(8): e0136822.

11. Lau, J.K., Zhang, X. and Yu, J. (2017) Animal models of non-alcoholic fatty liver disease: Current perspectives and recent advances. J. Pathol., 241(1): 36-44.

12. Mallaki, M., Norouzian, M.A. and Khadem, A.A. (2015) Effect of organic zinc supplementation on growth, nutrient utilization, and plasma zinc status in lambs. Turk. J. Vet. Anim. Sci., 39(1): 75-80.

13. Thornton, A.M. and Drummond, C.J. (2014) An unexpected case of pellagra. Med. J. Aust., 200(9): 546-548.

14. Hegazy, A.M., Hafez, A.S. and Eid, R.E. (2018) Protective and antioxidant effects of copper-nicotinate complex against glycerol-induced nephrotoxicity in rats. Drug Chem. Toxicol., https://doi.org/10.1080/01480545.2018.14 81084.

15. Nassar, A.Y., Ali, A.M., Nafady, A.A., El-Baz, M.A., Mohamed, Y.S., Abdel Latif, F.F., Hussein, A.M. and Nassar, M.Y. (2014) Copper (I)-nicotinate complex exhibits more prophylactic effect than butylated hydroxytoluene against nephrotoxicity in chronically aflatoxicosed rats. Glob. Ad Res. J. Med. Med. Sci., 3(9): 251-261.

16. Qusti, S.Y., Balgoon, M., Alzahrani, E.S., Elsawi, N., Alotaibi, N.A. (2018) Role of combined administration of copper-nicotinic acid complex and coenzyme q10 against aluminum chloride-induced oxidative stress in rat brain. Pharmacophore, 9(1): 19-29.

17. Abdel Hamid, A.A.M. and Soliman, M.F.M. (2015) Effect of topical Aloe vera on the process of healing of full-thickness skin burn: A histological and immunohistochemical study. J. Histol. Histopathol., 2:2-8.

18. Youssef, A.I. and Hassan, S.M. (2014) Copper-nicotinate complex ameliorates neurodegenerative cerebral cortex of rats. Glob. J. Pharmacol., 8(2): 245-255.

19. National Research Council. (1995) Nutrient Requirements of Laboratory Animals. $4^{\text {th }}$ ed. National Academies Press, US, Washington, DC

20. Farid, A.S. and Hegazy, A.M. (2019) Ameliorative effects of Moringa oleifera leaf extract on levofloxacin-induced hepatic toxicity in rats. Drug Chem. Toxicol., https://doi.org $/ 10.1080 / 01480545.2019 .1574811$.

21. Reitman, S. and Frankel, S. (1957) A colorimetric method for the determination of serum glutamic oxaloacetic and glutamic pyruvic transaminases. Am. J. Clin. Pathol., 28(1): 56-63.

22. Rosalki, S.B. and Rau, D. (1972) Serum $\gamma$-glutamyl transpeptidase activity in alcoholism. Clin. Chim. Acta, 39(1): 41-47.

23. Ellman, G.L. (1959) Tissue sulfhydryl groups. Arch. Biochem. Biophys., 82(1): 70-77.

24. Misra, H.P. and Fridovich, I. (1972) The role of superoxide anion in the autoxidation of epinephrine and a simple assay for superoxide dismutase. J. Biol. Chem., 247(10): 3170-3175.

25. Ohkawa, H., Ohishi, N. and Yagi, K. (1979) Assay for lipid peroxides in animal tissues by thiobarbituric acid reaction. Anal. Biochem., 95(2): 351-358.

26. Lowry, O.H., Rosenbrough, N.J., Lewis-Farr, A. and Randall, R.J. (1951) Protein measurement with the folin-phenol reagent. J. Biol. Chem., 193(1): 265-275.

27. Farid, A.S., Mido, S., Linh, B.K., Hayashi, T. and Horii, Y. (2010) An atherogenic lipid profile with low serum paraoxonase-1 activity during nematode infection in rats. Eur. J. Clin. Invest., 40(11): 984-993.
28. Schmittgen, T.D. and Livak, K.J. (2008) Analyzing real-time PCR data by the comparative C(T) method. Nat. Protoc., 3(6): 1101-1108.

29. Suvarna, K.S., Layton, C. and Bancroft, J.D. (2019) Bancroft's Theory and Practice of Histological Techniques e. Book. $8^{\text {th }}$ ed. Elsevier Ltd., Amsterdam, Netherlands. p672.

30. Milić, S., Lulić, D. and Štimac, D. (2014) Non-alcoholic fatty liver disease and obesity: Biochemical, metabolic and clinical presentations. World J. Gastroenterol., 20(28): 9330-9337.

31. Sumida, Y., Nakajima, A. and Itoh, Y. (2014) Limitations of liver biopsy and non-invasive diagnostic tests for the diagnosis of nonalcoholic fatty liver disease/nonalcoholic steatohepatitis. World J. Gastroenterol., 20(2): 475-485.

32. Stanković, M.N., Mladenović, D., Ninković, M., Ethuričić, I., Sobajić, S., Jorgačević, B., de Luka, S., Vukicevic, R.J. and Radosavljević, T.S. (2014) The effects of $\alpha$-lipoic acid on liver oxidative stress and free fatty acid composition in methionine-choline deficient diet-induced NAFLD. J. Med. Food, 17(2): 254-261.

33. Schierwagen, R., Maybüchen, L., Zimmer, S., Hittatiya, K., Bäck, C., Klein, S., Uschner, F.E., Reul, W., Boor, P., Nickenig, G., Strassburg, C.P., Trautwein, C., Plat, J., Lütjohann, D., Sauerbruch, T., Tacke, F. and Trebicka, J. (2015) Seven weeks of Western diet in apolipoprotein-E-deficient mice induce metabolic syndrome and non-alcoholic steatohepatitis with liver fibrosis. Sci. Rep., 5:12931.

34. Feng, W., Li, Q., Wang, W., Zhao, T., Feng, Y., Li, F., Mao, G., Chen, Y., Ding, Y., Yang, L. and Wu, X. (2018) Pharmacokinetics and bioavailability of chromium malate and its influence on trace metals absorption after oral or intravenous administration. Indian J. Pharmacol., 50(2): 75-83.

35. Chen, Q.L., Luo, Z., Wu, K., Huang, C., Zhuo, M.Q., Song, Y.F. and Hu, W. (2015) Differential effects of dietary copper deficiency and excess on lipid metabolism in yellow catfish Pelteobagrus fulvidraco. Comp. Biochem. Physiol. B Biochem. Mol. Biol., 184:19-28.

36. Sinthupoom, N., Prachayasittikul, V., Prachayasittikul, S., Ruchirawat, S. and Prachayasittikul, V. (2015) Nicotinic acid and derivatives as multifunctional pharmacophores for medical applications. Eur. Food Res. Technol., 240(1): 1-17.

37. Nassar, A.Y., Ali, A.M., El-Baz, M.A., Saad Eldien, H.M., Mohamed, Y.S., Abdel Latif, F.F., Hussein, A.M. and Nassar, M.Y. (2014) Copper (I)-nicotinate complex promoted the synthesis of aflatoxin M1 and Q1 more efficiently than butylated hydroxytoluene in afaltoxicosed rats. Glob. Adv. Res. J. Med. Med. Sci., 3(10): 298-307.

38. Vieira, S.A., Zhang, G., Eric, A. and Decker, E.A. (2017) Biological implications of lipid oxidation products. $J$. Am. Oil Chem. Soc., 94(3): 339-351.

39. Pawlak, M., Lefebvre, P. and Staels, B. (2015) Molecular mechanism of PPAR $\alpha$ action and its impact on lipid metabolism, inflammation and fibrosis in non-alcoholic fatty liver disease. J. Hepatol., 62(3): 720-733.

40. Buzzetti, E., Pinzani, M. and Tsochatzis, E.A. (2016) The multiple-hit pathogenesis of non-alcoholic fatty liver disease (NAFLD). Metabolism, 65(8): 1038-1048.

41. Pisoschi, A.M. and Pop, A. (2015) The role of antioxidants in the chemistry of oxidative stress: A review. Eur. J. Med. Chem., 97:55-74.

42. Dong, H., Guo, H., Liang, Y., Wang, X. and Niu, Y. (2017) Astragaloside IV synergizes with ferulic acid to suppress hepatic stellate cells activation in vitro. Free Radic. Res., 51(2): 167-178.

43. MacDonald, A.S., Straw, A.D., Dalton, N.M. and Pearce, E.J. (2002) Cutting edge: Th2 response induction by dendritic cells: A role for CD40. J. Immunol., 168(2): 537-540.

44. Bai, X., Yu, J.L., Wang, F., Zhao, Y., Liu, M.Y. and 
Wang, G.M. (2011) Alternatively activated macrophages in helminth infections. Zhongguo Ji Sheng Chong Xue Yu Ji Sheng Chong Bing Za Zhi, 29(3): 219-223.

45. Njoku, D.B. (2010) Suppressive and pro-inflammatory roles for IL-4 in the pathogenesis of experimental drug-induced liver injury: A review. Expert. Opin. Drug Metab. Toxicol., 6(5): 519-531.

46. Mosmann, T.R. and Moore, K.W. (1991) The role of IL-10 in cross regulation of TH1 and TH2 responses. Immunol. Today, 12(3): A49-A53.

47. dos Santos, D.C., da Silva Gomes Martinho, J.M., PachecoMoreira, L.F., Carvalho Viana de Araujo, C., CaroliBottino, A., Pannain, V.L., Trinta, K.S., Gandini, M., da Costa Neves, P.C., de Souza Matos, D.C., Caputo, L.F.G., Pelajo-Machado, M. and Pinto, M.A. (2009) Eosinophils involved in fulminant hepatic failure are associated with high interleukin-6 expression and absence of interleukin-5 in liver and peripheral blood. Liver Int., 29(4): 544-551.

48. Fisher, N.C., Neil, D.A., Williams, A. and Adams, D.H. (1999) Serum concentrations and peripheral secretion of the beta chemokines monocyte chemoattractant protein 1 and macrophage inflammatory protein 1alpha in alcoholic liver disease. Gut, 45(3): 416-420.

49. Khoruts, A., Stahnke, L., McClain, C.J., Logan, G. and Allen, J.I. (1991) Circulating tumor necrosis factor, interleukin-1 and interleukin-6 concentrations in chronic alcoholic patients. Hepatology, 13(2): 267-276.

50. Leifeld, L., Dumoulin, F.L., Purr, I., Janberg, K., Trautwein, C., Wolff, M., Manns, M.P., Sauerbruch, T. and Spengler, U. (2003) Early up-regulation of chemokine expression in fulminant hepatic failure. J. Pathol., 199(3): 335-344.

51. Simpson, K.J., Henderson, N.C., Bone-Larson, C.L., Lukacs, N.W., Hogaboam, C.M. and Kunkel, S.L. (2003) Chemokines in the pathogenesis of liver disease: So many players with poorly defined roles. Clin. Sci. (Lond), 104(1): 47-63.

52. Jiang, Y., Beller, D.I., Frendl, G. and Graves, D.T. (1992) Monocyte chemoattractant protein-1 regulates adhesion molecule expression and cytokine production in human monocytes. J. Immunol., 148(8): 2423-2428.

53. Salama, R.H.M., Nassar, A.Y.A., Nafady, A.A.M. and Mohamed, H.H.T. (2007) A novel therapeutic drug (copper nicotinic acid complex) for non-alcoholic fatty liver. Liver Int., 27(4): 454-464.

\section{$* * * * * * * *$}

